\title{
A Good Start to the Professional Career
}

Since its launch in 2006, Formula Student Germany has been regarded as a career springboard for budding engineers. Anyone who is successful in a team here has a good chance of joining an OEM, supplier or racing team immediately after graduating. At the Hockenheimring, companies actively advertise dozens of job vacancies to attract junior staff and students are crowded of the bulletin boards. Helena Herberth and Peter Jakowski work at Bosch Engineering in Abstatt. Here, the two former participants report on how Formula Student has influenced their entry into professional life.

\section{Helena Herberth I \\ Project Manager for Vehicle Dynamics Projects}

In the 2013/14 season, I supported the racing team of the University of Stuttgart in organizing and drawing up a business plan. Among other things, I designed the marketing strategy for our racing car and worked on all aspects of the organization of the club. I decided to continue supporting the team in the following 2014/15 season - I took over the team management and was the first chairman. So I was not only responsible for the acquisition and support of all sponsors but also for the administration and coordination of the whole club. This was a very intensive and instructive time for me, during which I learned to make decisions, tackle problems and solve them. As a team leader, I was also able to gain my first experience in personnel management.
The fact that the participation in the Formula Student was in my curriculum vitae was not decisive at first. In the application process, however, I was able to score points thanks to the multifaceted experiences I have gained during my FSG time, which ultimately enabled me to start my professional career.

I am currently working as a project manager for vehicle dynamics projects in the sports car sector. In my professional life, I can draw on all the experience I have acquired: solving problems constructively, being stress-resistant and relaxed, and being successful through motivation. It's nice to see that so many Formula Student alumni find their way to Bosch.

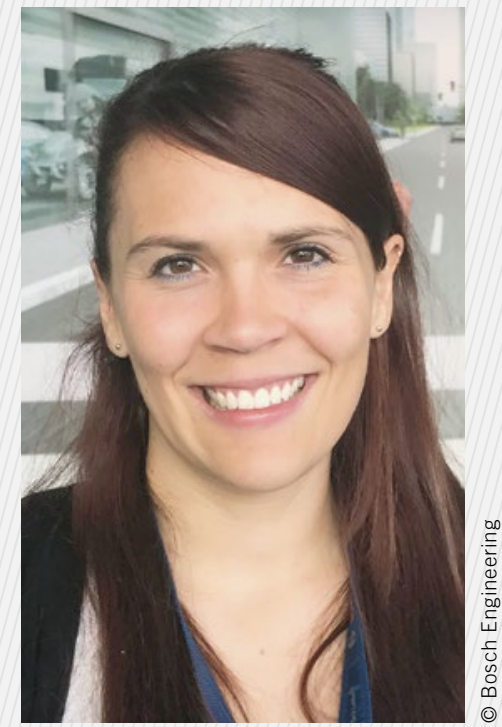

\section{Peter Jakowski I}

\section{Team and Project Manager for Driving Dynamics Projects}

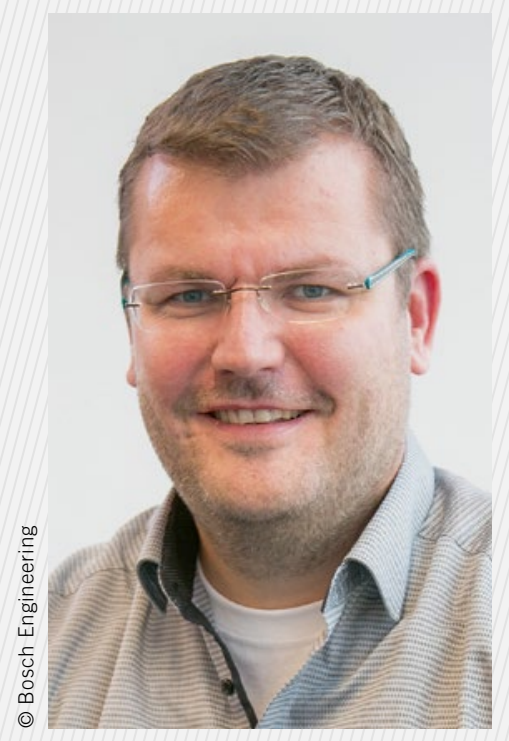

In 2005 I was one of the co-founders of Formula Student Germany, but my involvement in Formula Student already started in 2000 . At that time I accompanied the racing team of FH Stralsund in various positions at events in Great Britain and Australia. I learned a lot during this time. Not only was I able to improve my specialist knowledge, but I also gained initial experience in project planning and cost controlling. As a team leader, I often had to make difficult decisions and gained initial insights into personnel management. Both have brought me a lot for my current job as a team leader. Until this season, I have actively supported FSG in various areas, most recently as Head of Timekeeping/Scoring and in special tasks.

I have never been an active team member in the FSG, but was a founder and organizer.
Yet the participation in the Formula Student concept and my time in the Racing Team were extremely valuable and brought me closer to the practical side. Looking back, I don't think there could have been a better project for me to prepare for my job. After my studies, it was much easier for me to enter motorsport. Even when I finished my motorsport career after seven years and switched to Bosch Engineering, I was still able to draw on my team experience, both professionally and personally.

I am currently a team and project manager for driving dynamics projects in the sports car sector. The experience I gained during the FSG period, which I have built on in my professional life, is very useful to me and I regularly think back on this time. When I visit customers, I often meet people who are also involved in Formula Student - then you immediately have a topic for lunch together. 